\title{
THE CLINICAL SUPERVISION MODEL WITH CLASS ACTION APPROACH OF MICROTEACHING PROGRAM IN THE FKIP OF PGRI MADIUN UNIVERSITY
}

\author{
V. Teguh Suharto, Dwi Setiyadi, Elly's Mersina Mursidik, Ermi Adriani Meikayanti \\ Universitas PGRI Madiun \\ suharto_teguh@yahoo.com
}

\section{Article History}

accepted 30/09/2018

approved 12/10/2018

published 30/10/2018

Keywords

Clinical Supervision, Class

Action, Microteaching

\begin{abstract}
Educators have become the main agents in the duty of transfer of knowledge, character building and skill development for the learners to pursue intelligence, good personality, creativity and responsibility for the nation's welfare. The educators' role requires the prominent academic, pedagogycal and professional competence. Educators must be capable in designing and developing the proper instruction. To develop the educators' competence, educational institution needs to provide systematic, effective, and continuous trainings for the teacher candidates through microteaching and apprenticeship programs. Microteaching program enables candidates to practice peer-teaching in the campus, while apprenticeship program makes candidates apply teaching in school classes. The clinical supervision model with class action approach is relevant to characteristics and steps of microteaching program. Professional advice through systematic clinical service after teaching practice can effectively develop candidates' teaching skill, which motivates candidates to develop themselves in teaching practice.
\end{abstract}

Social, Humanities, and Education Studies (SHEs): Conference Series https://jurnal.uns.ac.id/shes
p-ISSN 2620-9284

e-ISSN 2620-9292 


\section{PENDAHULUAN}

Undang-undang nomor 20 tahun 2003 mewajibkan pendidik harus mampu menciptakan suasana pendidikan yang bermakna, menyenangkan, kreatif, dinamis, dan dialogis. Sesuai amanat ini, pendidik harus memiliki kompetensi pedagogis dan profesional yang memadai. Pendidik harus mampu merumuskan tujuan instruksional dan indikator-indikator yang terukur, organisasi materi, pemilihan metode, media, dan teknik evaluasi. Divsamping itu, juga harus mampu mengimplementasikan desain instruksional yang telah dibuat pada praktik pembelajaran di kelas (Sudjana, 2000: 5960 ). Tujuan di atas menuntut perlunya dikembangkan program pelatihan calon guru yang efektif, efisien, sistematis dan berkesinambungan melalui pembelajaran mikro dan PPL. Dalam pembelajaran mikro mahasiswa berlatih delapan keterampilan dasar mengajar di kampus, dan dalam PPL mahasiswa berlatih mengajar dan nonmengajar.

Pembelajaran mikro adalah studi tentang situasi pembelajaran yang dilaksanakan dalam empat sampai dua puluh menit dengan jumlah siswa sebanyak tiga sampai sepuluh orang, guru mengajar dengan satu konsep dan satu keterampilan mengajar (Hamalik, 2009: 145-151). Pembelajaran mikro adalah latihan praktik mengajar dalam lingkup kecil/ terbatas; secara bergantian diberikan latihan delapan keterampilan dasar mengajar; karena pengajarannya dikecilkan maka disebut micro teaching (Allen dan Ryan dalam Asril, 2010: 43-46). Pembelajaran mikro adalah peer teaching yang dilaksanakan oleh mahasiswa dalam waktu sekitar lima belas menit dengan jumlah siswa sebanyak delapan sampai sepuluh orang. Bentuk pengajaran sederhana, mahasiswa berada dalam kelas yang terbatas dan terkontrol. Calon guru hanya mengajarkan satu konsep dengan menggunakan satu atau dua ketrampilan mengajar. Diikuti untuk persiapan mahasiswa menempuh PPL (IKIP PGRI Madiun, 2013: 10).

Berdasarkan pendapat di atas, kata kunci pembelajaran mikro ialah: simulasi latihan mengajar, jumlah subjek belajar sekitar 8-10 mahasiswa, waktu mengajar sekitar 15 menit; bahan ajar terbatas, keterampilan mengajar terbatas, dilaksanakan di kelas yang terkontrol, diobservasi, ada umpan balik sehingga kelemahan praktik mengajar dapat segera diperbaiki, dan untuk persiapan mengikuti PPL.

Pembelajaran mikro ini bertujuan penting sebagai preservice learning bagi calon guru, yaitu untuk mempersiapkan ketrampilan mengajar para mahasiswa agar memiliki wawasan dan ketrampilan mengajar yang diperlukan untuk real teaching di sekolah. Menurut Remesh (2013: 158) microteaching is a teacher training technique forlearning teaching skills. It employs real teaching situation for developing skills and helps to get deeper knowledge regarding the art of teaching. This training technique provides teachers an excellent opportunity to improve their teaching skills (Remesh, 2013: 159).

Otsupius (dalam Koross, 2016: 290) menyatakan the complexity of a teaching situation can be overwhelming, hence to deal effectively with it, teachers must not only have a good knowledge of the subject in hand, but also some communication skills such as ability to observe, supervise, lead a discussion and pose questions. All these skills can be attained by the use of micro teaching technique while training. Micro teaching has an important place in preparation for the teaching profession because of its potential to emphasize the relationship between theory and practice. Relevan dengan pernyataan ini, Mastromarino dalam Mahmud \& Rawshon (2014: 69-70) berpendapat bahwa microteaching is used in the field of therapy to help convert theoretical knowledge into practical applications during interaction with patients. Getting a degree, which includes paratica, internships, and work study programs, is not always enough to prepare new teachers for the classroom experience (Le Maistre \& Paré, 2010). Newcomers to the teaching profession must be prepared for the experience through a transition process. Berdasarkan pendapat ini, dapat dirumuskan kegunaan pembelajaran mikro yaitu sebagai strategi latihan mempraktikan teori menjadi keterampilan mengajar. 
Secara rinci pengajaran mikro bertujuan: (1) memberi latihan sejumlah keterampilan dasar mengajar; (2) mengembangkan keterampilan mengajar sebelum terjun; (3) memberikan kemungkinan untuk mendapatkan bermacam-macam keterampilan dasar mengajar (Allen dalam Asril, 2010: 46). Karena pentingnya peranan untuk pelatihan calon guru, pembelajaran mikro perlu mendapatkan pengawasan dan bimbingan. Fteiha dan Abdawi (2017: 12) menyatakan "Hence, educational supervision is considered an essential pillar in the education system due to the liability relying upon the educational supervisor in following up with enforcing the educational - learning policy including all its merits; so as to realize the prospective educational goals".

Secara konseptual pembelajaran mikro dapat diartikan sebagai cara latihan keterampilan keguruan atau praktik mengajar dalam lingkup kecil/ terbatas (Knight dalam Asril, 2010: 43). Dalam konsepnya sebagai suatu latihan, pola supervisi klinis tepat sekali diterapkan untuk memberikan bimbingan kepada calon guru. Hal ini karena supervisi klinis merupakan bentuk bimbingan profesional yang diberikan kepada praktikan (calon guru) berdasarkan kebutuhannya melalui siklus yang sistematis dengan segera setelah praktik mengajar (Krajewskidalam Bafadal, 2003: 65). Selain itu, juga ditunjang dengan adanya pengawasan yang dikelola dengan baik dalam bentuk monitoring dan evaluasi pelaksanaan agar tidak melenceng dari jalur.

Berkaitan dengan konsep di atas, supervisi klinis dapat dijadikan model bimbingan/ pembelajaran mikro. Hal ini karena supervisi klinis yang memiliki konsepsi sendiri, dapat menjadi cara pandang/ gambaran mental bagaimana bimbingan/ pembelajaran mikro itu dilaksanakan secara supervisi klinis. Dorin, Demmin, dan Gabel (dalam Mergel, 1998: 2) secara umum menyatakan bahwa "a model is a mental picture that helps us understand somethink we cannot see or experience directly". Model adalah gambaran mental yang membantu memahami dan melaksanakan sesuatu yang tidak dapat dilihat atau pengalaman langsung. Ditinjau dari ciri maupun unsur pembangun supervisi klinis, maka supervisi klinis dapat dijadikan model karena supervisi klinis memenuhi ciri-ciri dan unsur-unsur yang harus ada pada suatu model.

Supervisi klinis merupakan bentuk bimbingan profesional yang diberikan kepada praktikan (calon guru) berdasarkan kebutuhannya melalui siklus yang sistematis dengan segera setelah praktik mengajar secara khusus melalui tatap muka dengan praktikan (Krajewski dalam Bafadal, 2003: 65; Sahertian, 2008: 36). Supervisi klinis dilakukan untuk memperkecil jurang antara perilaku mengajar nyata dengan perilaku mengajar seharusnya yang ideal. Supervisi klinis diharapkan dapat menolong guruguru (atau dalam hal ini adalah mahasiswa calon guru) agar mengerti inovasi dan mengubah penampilan mereka sehingga cocok dengan inovasi itu.

Supervisi klinis lahir karena adanya adanya sejarah buruk mengenai supervise. Cuenca (dalam Gursoy, Salihoglu, Kesner, 2016: 62) menginformasikan bahwa supervisors are mostly left alone with little or no training and are left to their own devices in their efforts to establish their pedagogical perspectives. Dalam masa sebelumnya, supervise dianggap misterius, sehingga lahir supervise klinis untuk mengatasi persoalan. This has raised the dissatisfaction of some educators until the seventies, which has led to the emergence of clinical supervision (Ebaidat \& Abu AlSmeid dalam Fteiha \& Abdawi, 2007: 12).

Supervisi klinis dilakukan untuk membantu pengembangan profesional guru dalam pengenalan mengajar melalui observasi dan analisis data secara objektif dan teliti sebagai dasar untuk mengubah perilaku mengajar guru. Klinis/ klinik identik dengan menangani orang sakit yang perlu diagnosis, untuk menemukan aspek-aspek mana yang membuat guru itu tidak dapat mengajar dengan baik. Kemudian aspekaspek itu satu per satu diperhatikan secara intensif. Supervisi klinis merupakan suatu model supervisi untuk menyelesaikan masalah mengajar berdasarkan hasil observasi. 
Supervisi klinik diwujudkan dalam bentuk hubungan tatap muka antara supervisor dan calon guru yang sedang berpraktik. In the words of Sergiovanni and Starratt (1979), "clinical supervision refers to face-to face encounters with teachers about teaching, usually in c1assrooms (Maitre, 2007: 50). Menurut Cogan (1973: 54) supervisi klinik yang dilaksanakan meliputi lima aspek, yaitu proses supervisi klinik, interaksi antara calon guru dan murid, performansi calon guru dalam mengajar, hubungan calon guru dengan supervisor, dan analisis data berdasarkan peristiwa aktual di kelas.

Asumsi yang menjadi alasan perlunya dilakukan supervisi klinik ialah: (1) Pengajaran merupakan aktivitas yang sangat kompleks yang memerlukan pengamatan dan analisis secara serius. Melalui pengamatan dan analisis ini, supervisor akan mudah mengembangkan kemampuan guru dalam praktik pembelajaran. (2) Guru-guru yang profesionalnya ingin dikembangkan lebih menghendaki cara yang kolegial daripada cara yang outoritarian (Sergiovanni, 1987: 4). Berdasarkan asumsi tersebut, supervisi klinik dirancang sebagai salah satu model atau pendekatan dalam melakukan supervisi pengajaran terhadap calon guru yang sedang berpraktik mengajar.

Sesuai dengan konsep dan kegunaannya, supervisi klinis di LPTK digunakan dalam bimbingan microteaching. Dengan supervisi klinis, mahasiswa peserta microteaching akan menemukan sendiri cara-cara meningkatkan kompetisinya melalui analisis (sharing) bersama (dosen, guru pamong, dan mahasiswa praktikan). Dalam supervisi klinis, guru dan dosen tidak boleh merasa sebagai instruktur yang otoritas, tetapi harus relasi kolegial, interaktif yang bersifat demokratis. Proses pembimbingan selalu datang dari mahasiswa sesuai dengan kebutuhan mereka dan bersifat deskriptif analitik (bukan evaluatif). Guru dan dosen tidak banyak memberikan ceramah atau intruksi, yang sebaliknya mahasiswalah yang aktif bertanya untuk analisis diri.

Bimbingan/ pembelajaran mikro yang dikemas dalam model supervisi klinis, dapat dilaksanakan dengan pendekatan tindakan kelas (PTK). Hal ini dapat dilaksanakan sebab langkah-langkah PTK mirip dan aplikatif dipadukan dengan supervisi klinis. Hal ini berasalan karena PTK adalah suatu bentuk kajian yang bersifat reflektif oleh pelaku tindakan untuk meningkatkan kemantapan rasional dari tindakan mereka dalam melaksanakan tugas, memperdalam pemahaman terhadap tindakantindakan yang dilakukan.

Pendekatan tindakan kelas ini diangkat dan dikombinasikan dengan model supervisi klinis karena penelitian tindakan kelas memiliki tujuan yang relecan, antara lainsebagai berikut: (a) meningkatkan mutu isi, masukan, proses, serta hasil pembelajaran di sekolah dan mengatasi masalah; (b) membantu guru dan tenaga kependidikan di dalam dan luar kelas; (c) meningkatkan sikap profesional pendidik dan tenaga kependidikan; (d) menumbuhkembangkan budaya akademik di lingkungan sekolah melakukan perbaikan mutu sehingga tercipta sikap proaktif di dalam melakukan perbaikan mutu pendidikan dan pembelajaran secara berkelanjutan (sustainable). Tujuan PTK di atas, disimpulkan dengan mengacu kepada Kemmis (dalam Wiriaatmadja, 2007: 12) yang menyatakan bahwa penelitian tindakan adalah studi sistematik tentang upaya memperbaiki praktik pendidikan melalui kerja praktik mereka sendiri dan merefleksinya untuk mengetahui pengaruh kegiatan tersebut terhadap praktik pembelajaran.

\section{METODE}

Prosedur pelaksanaan pembelajaran mikro terdiri dari lima langkah, yaitu (1) pemahaman konsep pengajaran mikro, (2) penyajian model dan diskusi, (3) perencanaan mengajar, (4) praktik, (5) diskusi umpan balik (Asril, 2010: 53). Mirip lima langkah tersebut, Mahmud \& Rawshon (2013: 69) membagi (1) role playing and video or audio recording, (2) self observational and/or supervision (monitoring), (3) reinforcement (dissonance), (4) re experimentation, and (5) practice of the acquired abilities. 
Dari langkah-langkah tersebut, secara lengkap dikembangkan oleh Universitas PGRI Madiun (2013: 15) sebagai berikut: (1) diskusi tentang "penampilan" guru yang baik dan analisis unsur-unsur ketrampilan mengajar; (2) pemberian model penampilan guru mengajar; (3) membuat silabus/ rencana pem-belajaran; (4) praktik mikro; (5) evaluasi/diskusioleh observers; (6) memperbaiki silabus/rencana pembelajaran; (7) praktik mikro ulang; (8) evaluasi diskusi ulang.

Pada intinya penilaian terhadap pembelajaran mikro terdiri dari dua bagian, yaitu (1) persiapan pembelajaran; (2) pelaksanaan praktik mengajar. Rincian penilaian tersebut meliputi: (1) perencanaan pembelajaran (silabus dan RPP), (2) keterampilan membuka pelajaran, (3) keterampilan bertanya, (4) keterampilan menguasai dan menjelaskan materi, (5) keterampilan menggunakan media, (6) keterampilan menggunakan metode dan strategi, (7) penampilan (gaya dan pakaian), (8) keterampilan mengelola kelas, (9) keterampilan menggunakan bahasa, (10) volume suara, (11) penyimpulan dan evaluasi, (12) kemampuan menutup pelajaran (Asril, 2010: 51).

Secara umum, penelitian ini menggunakan metode research and development ( $R$ and D), untuk menciptakan atau memperbaiki produk (Sukmadinata, 2007: 164). Borg dan Gall (1979: 626) menjelaskan ada 10 langkah pengembangan model pembelajaran. Mengacu pendapat tersebut, penelitian ini menggunakan 4 tahap yaitu tahap eksplorasi (langkah 1 dan 2); tahap pengembangan draft model (langkah 3); tahap pengujian model (langkah 4, 5, 6, 7, 8, 9); dan tahap diseminasi (langkah 10).

Pada penelitian pengembangan tahun kedua ini, dilakukan pengujian model (langkah 4, 5, 6, 7, 8, 9). Metode penelitian pada tahap uji terbatas dengan observasi langsung pada peristiwa pembelajaran menggunakan draf model untuk mengetahui dan merevisi keterbacaan model. Sedangkan metode penelitian pada uji luas adalah dengan metode eksperimen semu dengan membandingkan kelompok eksperimen dan kelompok kontrol. Instrumen pengambilan data menggunakan menngunakan lembar observasi supervisi klinis. Uji persyaratan analisis terdiri dari uji normalitas (menggunakan metode Kolmogorov-Smirnov) dan homogenitas (menggunakan Levene's test of equality of error variances), dan uji inferensial mengunakan statiktik ttes satu ekor kanan (right one tiled t-test).

\section{HASIL DAN PEMBAHASAN}

Supervisi klinis untuk memperbaiki perilaku calon guru yang kronis, artinya perilaku yang tidak kronis bisa diperbaiki dengan teknik supervisi yang lain; menyediakan umpan balik secara objektif bagi calon guru tentang kegiatan proses pembelajaran yang dilakukannya sebagai cermin agar calon guru dapat melihat apa yang dilakukan agar segera dapat memberi respon positif; mendiagnosis dan memecahkan berbagai problema yang dihadapi dalam proses pembelajaran. Ryan, \& Gottfried (dalam Fteiha \& Abdawi, 2017: 12) menyatakan bahwa the term "supervisor" as a person who assists, guides, directs and supervises a group of individuals he leads, he is not only liable for supervising the acts of these individuals, but also for understanding the beliefs and attitudes of his subordinates.

Supervisi klinis memiliki enam karakteristik yang membedakan dengan supervisi yang lain. Karakteristik itu adalah 1) supervisi klinis berlangsung dalam bentuk hubungan tatap muka antara supervisor dan guru; 2) tujuan supervisi klinis adalah untuk pengembangan profesional guru; 3) kegiatan supervisi klinis ditekankan pada aspek-aspek yang menjadi perhatian guru serta observasi kegiatan pengajaran di kelas; 4) observasi harus dilakukan secara cermat dan mendetail; 5) analisis terhadap hasil observasi harus dilakukan bersama antara supervisor dan guru; 6) hubungan antara supervisor dan guru harus bersifat kolegial bukan otoritarian (Bafadal, 2003: $67)$. 
Sesuai hal di atas, ternyata supervisi klinis dapat memperbaiki proses pembelajaran yang kronis. Hal itu, didukung dari peranan supervisi klinis dalam pembelajaran mikro, yaitu (1) memberikan informasi riil kepada mahasiswa tentang kompetensinya dalam menyusun silabus, RPP, dan praktik mengajar; (b) memberikan pertimbangan kepada mahasiswa tentang kelemahan yang masih dimilikinya dan bagaimana alternatif untuk meningkatkan kompetensinya menjadi lebih baik; (c) memberikan bimbingan kepada calon guru berdasarkan kebutuhannya sesuai balikan secara cepat dan objektif.

Supervisi klinis, memberikan bantuan yang bukan bersifat instruksi atau perintah, tetatpi tercipta hubungan manusiawi sehingga guru-guru memiliki rasa aman; apa yang akan disupervisi itu timbul dari harapan dan dorongan dari guru sendiri karena dia memang butuh bantuan itu; satuan tingkah laku mengajar yang dimiliki guru merupakan satuan yang terintegrasi, harus dianalisis sehingga terlihat kemampuan apa, keterampilan apa yang spesifik yang harus diperbaiki; suasana dalam pemberian supervisi adalah suasana yang penuh kehangatan, kedekatan, dan keterbukaan; supervisi yang diberikan tidak saja pada keterampilan mengajar tapi juga mengenai aspek-aspek kepribadian guru; instrumen yang digunakan untuk observasi disusun atas dasar kesepakatan antara supervisor dan guru; balikan yang diberikan harus secepat mungkin dan sifatnya objektif; dan dalam percakapan balikan seharusnya datang dari pihak guru lebih dahulu, bukan dari supervisor (Sahertian, 2008: 38).

Hasil pelaksanaan supervisi klinis pada pembelajaran mikro dapat dituliskan dalam tiga aktivitas. Tiga aktifitas esensial proses supervisi klinis, yaitu (1) tahap pertemuan awal, (2) tahap observasi mengajar, dan (3) tahap pertemuan balikan/evaluasi atau akhir.

(1) Tahap Pertemuan Awal

Secara teknis, ada delapan kegiatan yang harus dilaksanakan dalam pertemuan awal ini, yaitu menciptakan suasana yang akrab dan terbuka, mengidentifikasi aspek-aspek yang akan dikembangkan guru dalam pengajaran. menerjemahkan perhatian guru ke dalam tingkah laku yang bisa diamati, mengidentifikasi prosedur untuk memperbaiki pengajaran guru, membantu guru memperbaiki tujuannya sendiri menetapkan waktu observasi kelas, menyeleksi instrumen observasi kelas, dan memperjelas konteks pengajaran dengan melihat data yang akan direkam. Goldhammer, Anderson, dan Krajewski (dalam Depdiknas, 2008: 38) mendeskripsikan agenda yag harus dihasilkan pada pertemuan awal, yaitu:

a. Menetapkan persetujuan antara supervisor dan guru tentang apa saja yang akan diobservasi. Hal ini meliputi: tujuan instruksional umum dan khusus pengajaran; hubungan tujuan pengajaran dengan keseluruhan program pengajaran yang diimplementasikan; aktivitas yang akan diobservasi; kemungkinan perubahan formal aktivitas, sistem, dan unsur-unsur lain berdasarkan persetujuan interaktif antara supervisor dan guru; deskripsi spesifik butir-butir atau masalah-masalah yang balikannya diinginkan guru.

b. Menetapkan mekanisme atau aturan-aturan observasi meliputi waktu (jadwal) observasi, lamanya observasi, tempat observasi

c. Menetapkan rencana spesifik untuk melaksanakan observasi.Hal ini meliputi dimana supervisor akan duduk selama observasi; akankah supervisor menjelaskan kepada murid-murid mengenai tujuan observasinya jika demikian, kapan sebelum ataukah setelah pelajaran; akankah supervisor mencari satu tindakan khusus; akankah supervisor berinteraksi dengan muridmurid; perlukah adanya material atau persiapan khusus; bagaimanakah supervisor akan mengakhiri observasi 
(2) Tahap Observasi Pembelajaran

Observasi harus dilakukan secara sistematis dan objektif. Observasi ini ditujukan pada (1) guru dalam bertindak dan (2) kegiatan-kegiatan kelas sebagai hasil tindakan guru. Waktu dan tempat observasi mengajar ini sesuai dengan kesepakatan bersama antara supervisor dan guru pada waktu mengadakan pertemuan awal.

Menurut Daresh (dalam Depdiknas 2008: 39-41) ada dua aspek yang harus dilaksanakan oleh supervisor sebelum dan sesudah melaksanakan observasi mengajar, yaitu (1) menentukan aspek-aspek yang akan diobservasi, dan (2) bagaimana teknik dan instrumen mengobservasi. Aspek-aspek yang akan diobservasi harus sesuai dengan hasil diskusi antara supervisor dan guru pada waktu pertemuan awal. Masalah teknik, Acheson dan Gall (dalam Depdikbud, 2008: 22) mengemukakan beberapa teknik, yaitu: (a) selective verbatim, (b) rekaman observasional berupa seating chart, (c) wide-lens techniques, (d) checkliss (Flanders) and timeline coding technique.

Observasi harus memperhatikan pinsip antara lain: (1) harus luwes, (2) tidak mengganggu proses pembelajaran, (3) tidak bersifat menilai, (4) mencatat dan merekam hal-hal yang terjadi dalam proses pembelajaran sesuai kesepakatan bersama, dan (5) menentukan teknik pelaksanaan observasi.

(3) Tahap Pertemuan Balikan

Pertemuan balikan penting untuk mengembangkan perilaku calon guru. Balikan ini harus deskriptif, spesifik, konkrit, bersifat memotivasi, aktual, dan akurat sehingga betul-betul bermanfaat bagi guru (Sergiovanni dalam Depdiknas 2008: 42). Ada lima manfaat menurut Goldhammer, Anderson, dan Krajewski (dalam Depdiknas 2008: 42), yaitu, (1) guru bisa diberik penguatan dan kepuasan, sehingga bisa termotivasi dalam kerjanya, (2) isu-isu dalam pengajaran bisa didefinisikan bersama supervisor dan guru dengan tepat, (3) supervisor bila mungkin dan perlu, bisa berupaya mengintervensi secara langsung guru untuk memberikan bantuan didaktis dan bimbingan, (4) guru bisa dilatih dengan teknik ini untuk melakukan supervisi terhadap dirinya sendiri, dan (5) guru busa diberi pengetahuan tambahan untuk meningkatkan tingkat analisis profesional diri pada masa yang akan datang.

Berikut ini beberapa langkah penting yang harus dilakukan selama pertemuan balikan menurut Depdikbud (2008: 25-26).

a. Menanyakan perasaan guru secara umum atau kesannya terhadap pengajaran yang dilakukan, kemudian supervisor berusaha memberikan penguatan (reinforcement).

b. Menganalisa pencapaian tujuan pengajaran. Di sini supervisor bersa- ma guru mengidentifikasi perbedaan antara tujuan pengajaran yang direncanakan dan tujuan pengajaran yang dicapai.

c. Menganalisa target keterampilan dan perhatian utama guru. Di sini (supervisor bersama guru mengidentifikasi target ketrampilan dan perhatian utama yang telah dicapai dan yang belum dicapai. Bisa jadi pada saat ini supervisor menunjukkan hasil rekaman observasi, sehingga guru mengetahui apa yang telah dilakukan dan dicapai, dan yang belum sesuai dengan target ketrampilan dan perhatian utama guru sebagaimana disepakati pada tahap pertemuan awal. Apabila dalam kegiatan observasi supervisor merekam proses belajar mengajar dengan alat elektronik, misalnya dengan menggunakan alat syuting, maka sebaiknya hasil rekaman ini dipertontonkan kepada guru sehingga ia dengan bebas melihat dan menafsirkannya sendiri.

d. Supervisor menanyakan perasaannya setelah menganalisis target keterampilan dan perhatian utamanya. 
e. Menyimpulkan hasil dari apa yang telah diperolehnya selama proses supervisi klinik. Di sini supervisi memberikan kesempatan kepada guru untuk menyimpulkan target keterampilan dan perhatian utamanya yang telah dicapai selama proses supervisi klinis.

f. Mendorong guru untuk merencanakan latihan-latihan berikut sekaligus menetapkan rencana berikutnya.

Dalam pertemuan balikan ini, hal yang harus diperhatikan: (1) memberi penguatan; (2) mengulas kembali tujuan pembelajaran; (3) mengulas kembali hal-hal yang telah disepakati bersama, (4) mengkaji data hasil pengamatan, (5) tidak bersifat menyalahkan, (6) menyimpan data hasil pengamatan (tidak disebarluaskan), (7) menyimpulkan, (8) menghindari saran secara langsung, dan (9) merumuskan kembali kesepakatan-kesepakatan sebagai tindak lanjut proses perbaikan.

Tiga aktifitas esensial proses supervisi klinis di atas dilaksanakan dalam siklus Pendekatan Tindakan Kelas (PTK). Siklus pada PTK yang terdiri dari empat langkah, yaitu Planning (Rencana), Action (Tindakan), Observation (Pengamatan), Reflection (Refleksi), dalam pengembangan ini digunakan sebagai basis atau dasar pengembangan. Pelaksanaan supervisi klinis yang dikembangkan dengan empat langkah tersebut memberi rel pada pelaksanaan supervisi klinis. Ilustrasinya dapat dilihat pada tabel berikut.

Tabel 1: Rincian Skenario Supervisi Klinis dengan Pendekatan PTK

\begin{tabular}{ll}
\hline $\begin{array}{c}\text { Langkah } \\
\text { PTK }\end{array}$ & Langkah Pembelajaran Mikro \\
\hline Refleksi & \\
$\begin{array}{l}\text { Awal dan } \\
\text { Plan }\end{array}$ & $\begin{array}{l}\text { 1. Diskusi tentang } \\
\text { "penampilan" guru yang } \\
\text { baik dan analisis unsur- } \\
\text { unsur ketrampilan }\end{array}$ \\
& $\begin{array}{l}\text { mengajar } \\
\text { 2. Pemberian contoh atau } \\
\text { model penampilan guru } \\
\text { mengajar }\end{array}$ \\
& \\
& 3. Praktikan diberi tugas \\
& untuk membuat persiapan \\
& mengajar (silabus dan \\
& RPP) untuk praktik mikro
\end{tabular}

Do and Se Praktik mikro

Rincian Urutan Skrenario Supervisi Klinis

1. Dosen memimpin diskusi awal secara kelompok mengenai model penampilan guru yang baik dan unsur-unsur keterampilan mengajarnya dengan tempat dan suasana santai, akrab, dan terbuka selama 20-39 menit.

2. Dosen memberi kepercayaan kepada praktikan bahwa dengan supervisi, praktikan akan maju

3. Secara individual dosen mengidentifikasi dan memperjelas RPP (tujuan matode, waktu, aktivitas, media, evaluasi, dan lainlain yang terkait dengan pelajaran) yang akan digunakan dalam praktik mikro

4. Dosen dan praktikan menyepakati teknik, aturan, instrumen observasi, waktu,tahap, lama, tempat, dan objek observasi

Dosen dan kelompok mahasiswa, sambil berperan sebagai siswa, melakukan observasi sesuai kesepakatan serta mencatat kejadian dan perilaku praktikan dan reaksi murid yang penting 


$\begin{array}{ll}\text { Refleksi } & \text { Evaluasi/diskusi/kritik oleh } \\ \text { Akhir } & \begin{array}{l}\text { observer (merupakan umpan } \\ \text { balik) }\end{array}\end{array}$

Tugas memperbaiki Silabus dan RPP untuk putaran II (perbaikan)
1. Dosen menanyakan perasaan/kesanpraktikan secara umumterhadap pelajaran yang dilakukan dan memberi penguatan

2. Dosen bersama praktikan dan kelompok praktikan secara interaktif sharing experience menganalisis dan mengidentifikasi tujuan yang ditetapkan dan kernyataan yang dicapai praktikan

3. Dosen bersama praktikan dan kelompok praktikan secara interaktif sharing experience menganalisis dan mengidentifikasi target keterampilan dan perhatian utama praktikan. Jika perlu putar rekaman pelajaran

4. Dosen menanyakan perasaan praktikan setelah analisis target kekerampilan dan perhatian utama praktikan

5. Dosen menyimpulkan hasil yang diperoleh dari proses supervisi

6. Dosen mendorong praktikan untuk memperbaiki perencanaan pembelajaran dan praktik mikro pada periode berikutnya.

\section{SIMPULAN}

Berdasarkan analisis statistik $t$ test satu ekor kanan dengan program SPSS Release 13 didapatkan nilai signifikansi $p$ (probabilitas value) sebesar 0,000. Kenyataan ini menunjukkan nilai signifikansi p lebih kecil dibanding taraf signifikansi $\propto$ $(0,000<0,05)$. Hal ini berarti terdapat perbedaan antara mahasiswa yang dibimbing dengan model konvensional dan model supervisi klinis-tindakan kelas. Jika dilihat perbandingan antar mean dan standar deviasinya, maka hal ini berarti pula bahwa mahasiswa yang dibimbing dengan model supervisi klinis-tindakan kelas lebih baik prestasi pembelajaran mikronya dibanding mahasiswa yang dibimbing dengan model konvensional.

\section{DAFTAR PUSTAKA}

Asril, Z. (2010). Micro Teaching. Jakarta: Rajawali Press.

Bafadal, I. (2003). Peningkatan Profesionalisme Guru Sekolah Dasar. Jakarta : Bumi Aksara.

Chauhan, S. S., (1979). Innovation in Teaching and Learning Process. New Delhi: Vikas Publishing Hause PVT.

Cogan, M.L. (1973). Clinical Supervision. Bootm: Houghton Mifflin Comp.

Depdiknas. (2008). Metode dan Teknik Supervisi. Jakarta: Dikdasmen.

Dilworth, J.B. (1992). Operations Management: Design, Planing and Control for Manufacturing.

Fteiha, A., Abdawi, N. (2017). "The Effectiveness of Clinical Supervision on Technology Teacher'S Professional Development in Jerusalem A Case Study". The Eurasia Proceedings of Educational \& Social Sciences (EPESS) ISSN: 2587-1730.

Gürsoy, E., Kesner, J.E., Salihoglu, U.M. (2016). "Clinical Supervision Model in Teaching Practice: Does it make a Difference in Supervisors' Performance". This 
SHEs: Conference Series 1 (2) (2018) 485-494

Journal Article is Posted at Research Online. http://ro.ecu.edu.au/ajte/vol41/iss11/5.

Hamalik. (2009). Manajemen Pengembangan Kurikulum. Bandung: Rosdakarya.

IKIP PGRI Madiun. (2013). Pedoman Praktik Kependidikan. Madiun UPK IKIP PGRI Madiun.

Joyce, B., Weil, M., Calhoun, E. (2000). Models of Teaching. USA: Library of Congress Cataloging-in- Publication Data.

Joyce, B., Weil, M., Calhoun, E. (2009). Model of Teaching: Model-Model Pengajaran Edisi 8 (Terjemahan Achmad Fawaid \& Ateilla Mirza). Yogyakarta: Pustaka Pelajar.

Koross, R. (2016). "Micro Teaching an Efficient Technique for Learning Effective Teaching Skill: Pre-service Teachers Perspective". IRA International Journal of Education \& Multidiciplinary Studies. ISSN 2455, Vol 04, Issue 02 (2016) Pg no 289-299.

Maître. (2007). "Teacher Supervisionand The Concept of Clinical Supervision". Revue du CAMES- Nouvelle Série B. Vol. 008 № 1-2007 (1" Semestre).

Mahmud, I., Rawshon, S. (2013). "Micro Teaching to Improve Teaching Methot: An Analysis on Student's Perspective". IOSR Journal of Research \& Method in Education (IOSR-JRME) e-ISSN: 2320-7388,p-ISSN: 2320-737X Volume 1, Issue 4 (May. -Jun. 2013), PP 69-76 www.iosrjournals.org.

Mergel, B. (1998). The Instructional Design and Learning Theory (dalam http://www.usask.ca/educations/coursework/802papers/mergel/brenda.htm diunduh tanggal 11 Januari 2010).

Mosher, J.T., Purpel, D.E. (1972). Supervision: The Reluctant Profession. Boston: Honghton.

Sergiovanni, T.J., Starrat, R.J. (1979). Supervision: Human Perspective. New York: McGraw-Hill Book Company.

Sudjana, N. (2000). Dasar-dasar Proses Belajar Mengajar. Bandung: Sinar Baru.

Remesh, A. (2013). "Microteaching, and Efective Technique for Teaching Effective Teaching", Dalam Journal of Research in Medical Science, www.mui.ac.ir, diakses tanggal 8 September 2018.

Undang-undang Nomor 20 Tahun 2003 tentang Sistem Pendidikan Nasional Indonesia.

Wahab, A.A. (2008). Metode dan Model-Model Mengajar. Bandung: Alfabeta. 